\title{
Association between Fecal Incontinence and Lower Urinary Tract Symptoms and their Impact on the Quality of Life of Patients with Prostate Cancer
}

\author{
Natália Burgos Freire Azevedo ${ }^{10}$ Glícia Estevam de Abreu ${ }^{10}$ \\ ${ }^{1}$ Serviço Estadual de Oncologia (CICAN), Coloproctology \\ Department, Salvador, Bahia, Brazil \\ Address for correspondence Natália Burgos Freire Azevedo, Rua \\ Sócrates Guanaes Gomes, 140, apto. 202, Mansão Érico Veríssimo, \\ Candeal, Salvador - Bahia, Brasil (e-mail: nataliabfa@hotmail.com). \\ J Coloproctol 2022;42(1):32-37.
}

\begin{abstract}
Keywords

- prostate cancer

- radiotherapy

- radical prostatectomy

- urinary incontinence

- fecal incontinence

Objective To evaluate the association of fecal incontinence ( $\mathrm{FI}$ ) and lower urinary tract symptoms (LUTS) in patients diagnosed with initial prostate cancer (PC) and after any therapeutic approach (surgery and radiotherapy).

Methods Cross-sectional study using the Cleveland Clinic Incontinence Score (CCIS), the Fecal Incontinence Quality of Life (FIQL) questionnaire, and the International Consultation on Incontinence Questionnaire Overactive Bladder (ICIQ-OAB).

Results A total of 84 patients with PC were included: 40 of them had not started treatment, 31 were submitted to radical prostatectomy (RP), and 13 were submitted to radiotherapy (RT). Those submitted to RT presented higher scores on the ICIQ-OAB $(p=0.01)$. When comparing the whole sample reagarding the patients with and without $\mathrm{Fl}$, we observed that the incontinents presented a higher frequency of urinary incontinence (UI) $(p<0.001)$. Moreover, when comparing patients with/without $\mathrm{FI}$ within their treatment groups regarding the presence of UI and FIQL scores, we identified that patients undergoing RP presented an association between $\mathrm{UI}$ and $\mathrm{FI}$ $(p<0.001)$ and a greater impact of FI on the FIQL $(p<0.001)$.

Conclusion Patients submitted to RT present more intense LUTS. Moreover, patients with $\mathrm{FI}$ present a higher association with $\mathrm{UI}$, and this association is more marked in those with Fl submitted to RP.
\end{abstract}

\section{Introduction}

Patients with prostate cancer (PC), depending on their staging, may be referred for treatments that can lead to the onset or intensification of urinary and intestinal symptoms. ${ }^{1}$ Despite its favorable results, radiotherapy (RT) can cause several side effects, and intestinal and urinary symptoms are of significant importance, since they can compromise quality of life (QOL). ${ }^{2}$ Fecal incontinence $(\mathrm{FI})$ is one of the most common adverse effects, and its onset is associated with actinic proctitis. ${ }^{3}$ In turn, radical prostatectomy (RP) may also be responsible for complications, with sexual dysfunction and urinary incontinence (UI) being the postoperative symptoms that most impact QOL. ${ }^{1}$

The presence of FI or lower urinary tract symptoms (LUTS) after treatment for $\mathrm{PC}$ may compromise labor activities, as well as social interaction. ${ }^{2}$ Thus, there is an evident need to analyze the presence of FI and LUTS, as well as the association of these received

March 23, 2021

accepted after revision

August 6, 2021
DOI https://doi.org/

$10.1055 / \mathrm{s}-0042-1742620$

ISSN 2237-9363. (c) 2022. Sociedade Brasileira de Coloproctologia. All rights reserved.

This is an open access article published by Thieme under the terms of the Creative Commons Attribution-NonDerivative-NonCommercial-License, permitting copying and reproduction so long as the original work is given appropriate credit. Contents may not be used for commercial purposes, or adapted, remixed, transformed or built upon. (https://creativecommons.org/ licenses/by-nc-nd/4.0/)

Thieme Revinter Publicações Ltda., Rua do Matoso 170, Rio de Janeiro, RJ, CEP 20270-135, Brazil 
symptoms in patients with PC before and after any therapeutic approach. When addressing the frequency with which these symptoms occur and their association, there the implementation of approaches that not only improve the QOL of patients with $\mathrm{PC}$, but also prevent or mitigate the possible adverse effects resulting from the treatments, should be encouraged. Addressing the frequency and association between these symptoms will encourage the application of measures to avoid or reduce the adverse effects of treatments and, consequently, may reflect an improvement in the quality of life of patients.

\section{Methods}

\section{Patient selection}

A cross-sectional study was conducted with men with PC assisted by urologists at Serviço Estadual de Oncologia (CICAN), in the city of Salvador, state of Bahia, Brazil, from April 30th to September 4th, 2020. We included men over the age of 18 years who were scheduled for treatment (recent diagnosis) or who had undergone RT or RP in the last 5 years. Those with neurological and/or anatomical alterations of the urinary and/or digestive tracts, patients using laxatives, patients who had had RT associated with surgery, and those who did not fill out all questionnaires applied, in addition to functionally-illiterate patients, were excluded.

\section{Instruments used}

Before the beginning of the research, all interviewers were trained on questions related to intestinal and urological disorders, so that they could answer, through e-mails or telephone calls, the questions of men during the application of the questionnaire. Through telephone calls, the patients were evaluated regarding the inclusion and exclusion criteria, and those who were within the target group of the research were invited to participate. After agreeing provide informed consent, all respondents filled out the Google Forms questionnaire made available to them by message or email. The self-report instrument contained questions on age, type of treatment performed for PC, and presence of FI and LUTS, and did not allow patients to leave unanswered questions. The research team had no contact with the men prior to the interview, and no gastrointestinal or urological recommendations were provided to improve these dysfunctions.

To evaluate FI, the Cleveland Clinic Incontinence Score $(\mathrm{CCIS})^{4}$ was used, which contains five items to be evaluated: incontinence to liquids, solids, and gases, in addition to the use of liners and lifestyle alterations. The CCIS uses a Likert scale with scores ranging from never ( 0$)$, rarely ( 1 point), occasionally ( 2 points), frequently ( 3 points), and always ( 4 points). A score of 0 point indicates perfect continence; from 1 to 7 , mild incontinence; from 8 to 14 , moderate incontinence; and, from 15 to 20, severe incontinence.

The Fecal Incontinence Quality of Life (FIQL) ${ }^{5}$ questionnaire was used to assess the impact of FI on QOL. It consists of 29 questions divided into 4 domains. The scores of each item range from 1 to 4, except for questions 1 and 4, which have scores of 5 and 6 points respectively. The the final score, the better the QOL and the lower the impact on QOL. The final result is the sum of all points, where the smaller the score, the greater the perceived severity of fecal incontinence.

The LUTS were evaluated through the International Consultation on Incontinence Questionnaire Overactive Blader (ICIQ-OAB). ${ }^{6}$ This score also uses a Likert scale. In question 3a, the urinary frequency is evaluated as: 1-6 times (0); 7-8 times ( 1 point); 9 -10 times ( 2 points); $11-12$ times ( 3 points); and $\geq 13$ times ( 4 points). Men who report a urinary frequency of 9 times a day ( 2 points) are considered to have pollakiuria. In the $4 \mathrm{a}$, nocturia is analyzed: no time ( 0$) ; 1$ time ( 1 point); 2 times ( 2 points); 3 times ( 3 points); and $\geq 4$ times ( 4 points). Patients who get up more than 1 time a night ( 2 points) are classified as having nocturia. Finally, 5a and $6 a$ evaluate voiding urgency and UI respectively: never corresponds to 0 point; a few times, 1 point; sometimes, 2 points; most of the time, 3 points; and always, 4 points. Patients who answer "sometimes", "most of the time", or "always" are considered carriers of these symptoms. This questionnaire also enables the evaluation of the impact of LUTS on the QOL (questions 3b, $4 \mathrm{~b}, 5 \mathrm{~b}, 6 \mathrm{~b})$, with scores ranging from 0 to 10 points, in which zero corresponds to no impact, and 10 , to a high impact. As this part of the questionnaire contains 4 questions, its score ranges from 0 to 40 points, and the higher the score, the greater the impact on QOL. For the purposes of better understanding, we named this section of the questionnaire related to the impact of LUTS on QOL as the QOL score of the ICIQ-OAB.

\section{Statistical Analysis}

The statistical analysis was performed with the Statistical Package for the Social Sciences (IBM SPSS Statistics for Windows, IBM Corp., Armonk, NY, United States) software, version 21.0. The numerical variable representing age was expressed as a mean and standard deviation value, and the scores were expressed as medians and interquartile range (IQR). The variables included in the analysis were: age, patient subgroup (RT/RP/No treatment), urinary symptoms (urgency, incontinence, pollakiuria, and nocturia), FI, and the scores on the CCIS, the FIQL, and the ICIQ-OAB. Age, and the scores on the CCIS, the FIQL and the ICIQ-OAB were defined as quantitative variables. The patient subgroup, urinary symptoms, and FI were classified as categorical variables.

The calculation of the sample size considered a crosssectional study ${ }^{7}$ in which $5.9 \%$ of men diagnosed with PC presented FI and LUTS simultaneously. According to the hypothesis that $50 \%$ of these individuals would present lower urinary tract disorder and 50\% would not, the sample size was calculated as 83 men for a power of $80 \%$ and an alpha error of $5 \%$.

The Kruskal-Wallis test was used to evaluate the association between the scores and subgroups of patients. In turn, the Chisquared test evaluated the association between the subgroups of patients and urinary symptoms (pollakiuria, nocturia, voiding urgency, and UI) and FI, as well as the association between the presence of FI and LUTS. The Mann-Whitney test was used to evaluate the association between FI and the FIQL.

In addition, to evaluate the association of FI and perfect continence in relation to UI within the subgroups of patients, the Chi-squared test was used. To evaluate the association of FI and perfect continence in relation to the FIQL, the 
Mann-Whitney test was used. The associations regarding age and the scores on the CCIS, the FIQL and the QOL section of the ICIQ-OAB were evaluated through the Spearman correlation. Similarly, this test was used to evaluate the association between the scores on the CCIS and FIQL and between those of the ICIQ-OAB and QOL for urinary symptoms. Values of $p<0.05$ were considered statistically significant.

The Ethics Committee of Escola Bahiana de Medicina e Saúde Pública approved the study protocol under CAAE 26099319.4.0000.5544. Patients were only admitted to the study after virtually signing the informed consent form provided in the research form, which only allowed access to the questionnaires after approval of the term. All procedures performed in the present study were in accordance with the national and institutional ethical standards for research and with the Declaration of Helsinki of 1964 and its subsequent changes.

\section{Results}

We included a total of 84 patients (mean age: $67.5+7.7$ years) diagnosed with PC. Regarding treatment, of the 84 patients, 40 men had not yet started it (47.6\%), 31 were submitted to RP (36.9\%), and 13 patients underwent RT (15.5\%).

The median scores on the ICIQ-OAB, CCIS and FIQL were of 4 (IQR: 3-8), 0 (IQR: 0-1.75), and 116 (IQR: 115-117) respectively. A total of 25 patients (29.8\%) had mild anal incontinence according to the CCIS, with a median score of 3 (IQR: 2-5).

In the comparison of the groups of patients with PC, significant variations were found in the ICIQ-OAB score $(p=0.01)$, regarding patients submitted to RT, RP and those without treatment, with medians of 8 (IQR: 5-10.5), 4 (IQR: 37), and 4(IQR: $1.25-8$ ) respectively. In the other questionnaires, there was no difference among the groups. Neither were there differences among the groups in relation to the presence of LUTS (pollakiuria, nocturia, urgency and UI) and FI ( - Table 1 ).

However, when comparing patients with FI and those with perfect continence regarding the presence of LUTS and the FIQL and ICIQ-OAB scores, we observed that patients incontinent to feces had a higher frequency of $\mathrm{UI}(p<0.001)$ (-Table 2).

Evaluating the treatment groups regarding the presence of FI, we observed that patients submitted to RP presented an

Table 1 Intergroup comparison regarding the ICIQ-OAB, CCIS, and FIQL scores and presence of urinary symptoms and urinary and fecal incontinence

\begin{tabular}{|l|l|l|l|l|l|}
\hline Variable & & Radiotherapy & Radical prostatectomy & No treatment & $p$-value \\
\hline & & $\mathbf{n}=13$ & $\mathbf{n}=\mathbf{3 1}$ & $\mathbf{n}=\mathbf{4 0}$ & \\
\hline ICIQ-OAB & $(\mathrm{M} / \mathrm{IQR})$ & $8(5.0-10.5)$ & $4(3.0-7.0)$ & $4(1.25-8.0)$ & $0.01^{\mathrm{a}}$ \\
\hline CCIS & $(\mathrm{M} / \mathrm{IQR})$ & $0(0.0-3.0)$ & $0(0.0-1.0)$ & $0(0.0-1.75)$ & $0.78^{\mathrm{a}}$ \\
\hline FIQL & $(\mathrm{M} / \mathrm{IQR})$ & $116(115.0-116.5)$ & $116(114.0-117.0)$ & $116(115.0-117.0)$ & $0.75^{\mathrm{a}}$ \\
\hline Pollakiuria & $\mathrm{n}(\%)$ & $5(38.5)$ & $9(29.0)$ & $10(25.0)$ & $0.64^{*}$ \\
\hline Nocturia & $\mathrm{n}(\%)$ & $11(84.6)$ & $21(67.7)$ & $26(65.0)$ & $0.40^{*}$ \\
\hline Voiding urgency & $\mathrm{n}(\%)$ & $8(61.5)$ & $10(32.3)$ & $12(30.0)$ & $0.10^{*}$ \\
\hline Urinary incontinence & $\mathrm{n}(\%)$ & $6(46.2)$ & $10(32.3)$ & $10(25.0)$ & $0.35^{*}$ \\
\hline Fecal incontinence & $\mathrm{n}(\%)$ & $5(38.5)$ & $8(25.8)$ & $12(30.0)$ & $0.70^{*}$ \\
\hline
\end{tabular}

Abbreviations: CCIS, Cleveland Clinic Incontinence Score; FIQL, Fecal Incontinence Quality of Life questionnaire; ICIQ-OAB, International Consultation on Incontinence Questionnaire Overactive Bladder; IQR, interquartile range; M, median.

Notes: ${ }^{\text {a }}$ Kruskal-Wallis test. ${ }^{*}$ Chi-squared test.

Table 2 Comparison between patients with fecal incontinence and perfect continence for urinary symptoms and FIQL and ICIQ-OAB scores

\begin{tabular}{|l|l|l|l|l|}
\hline Variable & & Fecal incontinence & Perfect continence & $p$-value \\
\hline & & $\mathbf{n}=\mathbf{2 5}$ & $\mathbf{n}=\mathbf{5 9}$ & \\
\hline Pollakiuria & $\mathrm{n}(\%)$ & $9(36.0)$ & $15(25.4)$ & $0.32^{*}$ \\
\hline Nocturia & $\mathrm{n}(\%)$ & $16(64.0)$ & $42(71.2)$ & $0.51^{*}$ \\
\hline Voiding urgency & $\mathrm{n}(\%)$ & $12(48.0)$ & $18(30.5)$ & $0.12^{*}$ \\
\hline Urinary incontinence & $\mathrm{n}(\%)$ & $14(56.0)$ & $12(20.3)$ & $<0.001^{*}$ \\
\hline FIQL & $(\mathrm{M} / \mathrm{IQR})$ & $116(112.0-117.0)$ & $116(115.0-117.0)$ & $0.68+$ \\
\hline ICIQ-OAB & $(\mathrm{M} / \mathrm{IQR})$ & $7(3.5-11.5)$ & $4(3.0-7.0)$ & $0.08+$ \\
\hline
\end{tabular}

Abbreviations: FIQL, Fecal Incontinence Quality of Life questionnaire; ICIQ-OAB, International Consultation on Incontinence Questionnaire Overactive Bladder; IQR, interquartile range; M, median.

Notes: ${ }^{*}$ Chi-squared test. + Mann-Whitney test. 
association between UI and FI $(p<0.001)$ and a greater impact of urinary symptoms on QOL, measured by the QOL section of the ICIQ-OAB $(p=0.03)$. In addition, there was a greater impact of the presence of $\mathrm{FI}$ on $\mathrm{QOL}$ in this group of patients $(p<0.001)$ ( - Table 3$)$. However, when comparing the degrees of FI among the groups of patients, no difference was found (-Table 4).

No correlations were found between age and the scores on the ICIQ-OAB $(r=-0.42 ; p=0.70)$, the CCIS $(r=-0.23$; $p=0.83)$, and the FIQL $(r=-0.13 ; p=0.90)$. In turn, there was a weak negative correlation between the CCIS and FIQL scores $(\mathrm{r}=-0.256 ; p=0.01)$, and a strong positive correlation between the overall score on the ICIQ-OAB and the score on its QOL section $(\mathrm{r}=0.75 ; p<0.01)$.

\section{Discussion}

In the present study, we observed that the group of patients submitted to RT presented more intense LUTS, characterized by higher ICIQ-OAB scores. Moreover, in the evaluation of the entire sample, the presence of FI was associated with the presence of UI. It is also noteworthy that, in the evaluation of $\mathrm{FI}$, the patients incontinent to feces submitted to RP presented a greater association with UI, and there was also impairment of QOL related to fecal and urinary loss. Finally, a correlation was identified between the CCIS and FIQL scores and between the overall ICIQ-OAB score and the score on its QOL section, which demonstrates the impact of FI and LUTS on patient well-being, with urinary complaints having a more intense impact.

The most intense urinary complaints among the patients submitted to RT are possibly related to the presence of actinic lesions, and actinic cystitis is responsible for symptoms such as urgency, dysuria, and pollakiuria and, consequently, higher scores among this group of patients. ${ }^{3}$ Unlike the results obtained in the present study, the study by Potosky et al. ${ }^{8}$ identified that patients submitted to RP had a higher frequency of urinary complications (9.6\%) when compared to those submitted to RT (3.5\%). Still in divergence to our findings, Sanda et al., ${ }^{2}$ found that, compared to postradiotherapy UI, postsurgery UI had a greater impact on QOL. According to the same authors, ${ }^{2}$ the effects of RT on urinary symptoms usually resolve 12 months after the end of treatment, improving in relation to symptoms prior to 24 months of RT. Also studying patients with irradiated PC, Fonteyne et al. ${ }^{9}$ observed that the urinary symptoms present before treatment intensified during RT sessions, from grade 1 to grade 2 , in $48 \%$ of the cases, and that, after 1 and 2 years, $60 \%$ to $70 \%$ of the patients presented symptoms less intense than those felt before the treatment. The dissonant result of the present study can be explained by the fact that the date of the end of RT was not taken into account, although only patients undergoing treatment in the last 5 years were included, and the presence of recently-irradiated patients may have influenced the analysis. It is worth noting that Pinezi, ${ }^{10}$ in a study evaluating women submitted to RT for cervical neoplasia, observed that the diagnosis of actinic cystitis with intensity $\geq 2$ was more performed when to assess simulated

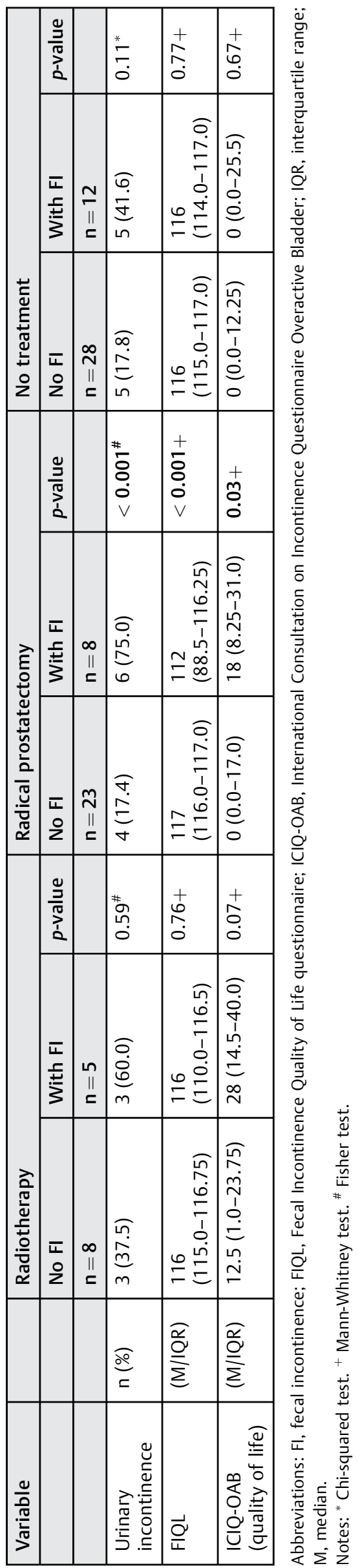


Table 4 Intergroup comparison of patients (radiotherapy/radical prostatectomy/untreated) regarding the degrees of fecal incontinence

\begin{tabular}{|c|l|l|l|l|l|}
\hline Variable & & Radiotherapy & Radical prostatectomy & No treatment & $p$-value \\
\hline & & $\mathrm{n}=13$ & $\mathrm{n}=31$ & $\mathrm{n}=\mathbf{4 0}$ & \\
\hline Degrees of incontinence: & & & & & $0.58^{*}$ \\
\hline Perfect continence & $\mathrm{n}(\%)$ & $8(61.5)$ & $23(74.2)$ & $28(70.0)$ & \\
\hline Mild incontinence & $\mathrm{n}(\%)$ & $5(38.5)$ & $6(19.4)$ & $11(27.5)$ & \\
\hline Moderate incontinence & $\mathrm{n}(\%)$ & 0 & $2(6.5)$ & $1(2.5)$ & \\
\hline Severe incontinence & $\mathrm{n}(\%)$ & 0 & 0 & 0 & \\
\hline
\end{tabular}

Note:* Chi-squared test.

symptoms by specific questionary. Thus, although the duration of the RT was not determined, the application of a specific questionnaire (the ICIQ-OAB) to evaluate the LUTS, may have enabled a better identification and analysis of these symptoms.

The physiological explanation for the concomitant occurrence of FI and UI is mainly due to advancing age and its consequences, such as increased prevalence of mental confusion, detrusor instability, poor mobility, cognitive decline, use of diuretics, and loss of pelvic support. ${ }^{11}$ In the study by Roberts et al., ${ }^{7}$ the prevalence of FI combined with UI was of $5.9 \%$ among men, with increased incidence with advancing age. In their cross-sectional study, Silva et al. ${ }^{12}$ identified that, of the 324 elderly patients evaluated, 33 (10.25\%) had UI, only 1 had isolated FI (0.31\%), and 120 (37.27\%) had double incontinence. Thus, it is possible to verify that there is still no consensus regarding the prevalence of this association. The difference between the studies may stem from the different definitions of incontinence proposed and the variability in the age of the patients involved.

In patients incontinent to stool submitted to RP, a higher incidence of UI and a negative impact on QOL were observed due to the presence of urinary and fecal losses. Several factors such as deficiency of the internal and external sphincters of the urethra, bladder dysfunction, and weakness of pelvic floor muscles may be implicated in the occurrence of UI in patients submitted to RP. ${ }^{13}$ During surgery, the sphincters may be injured; in addition, the external urethral sphincter may already be weakened due to the period in which the urethra was compressed by the enlarged prostate. ${ }^{13}$ The incidence of UI-associated FI, called double incontinence, may justify the impact on the patient's QOL, because the presence of double incontinence is related to depressive symptoms in men. ${ }^{11}$

Since the scores that assess LUTS and FI correlate with the scores that measure QOL, it has been demonstrated that the intensity of both directly affects the patient's life, but there is a greater impact on QOL related to the intensity of urinary symptoms. Changes in lifestyle occur in an attempt to adapt to the new reality, because urinary loss may cause anxiety, social/family distancing, and feeling of loss of control of one's own life. ${ }^{14}$ It is important to point out that the weak correlation found between the CCIS and FIQL scores in the present study can be explained by the fact that most (88\%) of the incontinent patients presented mild incontinence.
We also observed that $30 \%$ of the patients who had not yet been treated for PC already had FI. Since some treatments for PC may aggravate the patient's defecation complaints, previous knowledge about fecal loss is fundamental when choosing the best approach. Radiotherapy, for example, can cause intestinal discomfort, such as rectal urgency, increased frequency, pain, FI, and hematochezia within one year of treatment, which could intensify the intestinal complaint that already existed before the treatment. ${ }^{2}$ In turn, RP could cause, above all, LUTS, such as dysuria, voiding urgency, and urethritis, thus adding urinary complaints in patients with previous fecal symptoms, significantly reducing QOL. ${ }^{9}$ Therefore, the presence of FI prior to treatment should be considered when defining the therapeutic approach for PC.

One of the limitations of the present study is the lack of information about the time elapsed after each type of treatment, which could better explain some of the results found. Moreover, the fact that the study is observational makes it impossible to determine the causality involving the variables.

Therefore, the present study, with the evaluation of LUTS, FI and the association between them, provides more information about the presence of these symptoms in men with PC and how they interfere with QOL. Thus, the broad and individualized evaluation of men with PC can help in the choice of treatment, which should be defined according to the clinical picture and the desires of the patient, always considering the associated symptoms that may impact QOL.

\section{Conclusion}

In men with PC, LUTS are more intense in those submitted to RT. The presence of FI in men with PC is associated with the presence of UI, with QOL impairment, particularly in patients with FI undergoing RP.

\section{Conflict of Interests}

The authors have no conflict of interests to declare.

\section{References}

1 de Penha LS, de Penaforte NF, da Silva CS, et al. Câncer de Próstata: uma Revisão da Literatura. Int J Neurol 2018;11(01):S24-S327. Doi: $10.1055 / \mathrm{s}-0038-1674531$ 
2 Sanda MG, Dunn RL, Michalski J, et al. Quality of life and satisfaction with outcome among prostate-cancer survivors. N Engl J Med 2008;358(12):1250-1261. Doi: 10.1056/NEJMoa074311

3 Nadalin W. Algumas considerações sobre a retite actínica. Radiol Bras 2009;42(02):v-vi. Doi: 10.1590/S0100-39842009000200001 [Internet]

4 Nasseri YAP, Pescatori M. 2005Complex anorectal Disorders. Investigation and Management 2005. Available at: http://eknygos.lsmuni.lt/springer/97/Contents\%20and\%20Front\%20Matter. pdf

5 Yusuf SAI, Jorge JMN, Habr-Gama A, Kiss DR, Gama Rodrigues J. Avaliação da qualidade de vida na incontinência anal: validação do questionário FIQL (Fecal Incontinence Quality of Life). Arq Gastroenterol 2004;41(03):202-208. Doi: 10.1590/S000428032004000300013

6 Pereira SB, Thiel RdoR, Riccetto C, et al. validação do international consultation on incontinence questionnaire overactive bladder (iciq-oab) para a língua portuguesa. Rev Bras Ginecol Obstet 2010; 32(06):273-278. Doi: 10.1590/S0100-72032010000600004

7 Roberts RO, Jacobsen SJ, Reilly WT, Pemberton JH, Lieber MM, Talley NJ. Prevalence of combined fecal and urinary incontinence: a community-based study. J Am Geriatr Soc 1999;47(07): 837-841. Doi: 10.1111/j.1532-5415.1999.tb03841.x

8 Potosky AL, Legler J, Albertsen PC, et al. Health outcomes after prostatectomy or radiotherapy for prostate cancer: results from the Prostate Cancer Outcomes Study. J Natl Cancer Inst 2000;92 (19):1582-1592. Doi: 10.1093/jnci/92.19.1582
9 Fonteyne V, Villeirs G, Lumen N, De Meerleer G. Urinary toxicity after high dose intensity modulated radiotherapy as primary therapy for prostate cancer. Radiother Oncol 2009;92(01): 42-47. Doi: 10.1016/j.radonc.2009.03.013

10 Pinezi JCD. Efeitos colaterais tardios na bexiga após radioterapia por câncer de colo de útero: avaliação da associação com polimorfismos de TP53, ATM e MDM2. 2014. Available at: https:// teses.usp.br/teses/disponiveis/5/5151/tde-09012015-163553/ publico/JulianaCastroDouradoPineziVersaoCorrigida.pdf

11 Nunes AC. Avaliação da qualidade de vida em pacientes submetidos à prostatecomia radical assistida por robô: um estudo piloto. 2019. Available at: https://lume.ufrgs.br/bitstream/handle/ 10183/202746/001107296.pdf?sequence=1\&isAllowed=y

12 Silva MA, Aguiar ESS, Matos SDO, Lima JO, Costa MML, Soares MJGO. Prevalência de incontinência urinária e fecal em idosos: estudo em instituições de longa permanência para idosos. Capa 2016;21(01):249-261 Available at: https://www.seer.ufrgs.br/ RevEnvelhecer/article/viewFile/46484/40727

13 Gomes CRG, Eduardo AHA, Mosteiro-Diaz M-P, Pérez-Paniagua J, Napoleão AA. Intervenções de enfermagem para incontinência urinária e disfunção sexual após prostatectomia radical. Acta Paul Enferm 2019;32(01):106-112.Doi:10.1590/1982-0194201900015 14 Bernardes MFVG, de Chagas SC, de Izidoro LCR, Veloso DFM, Chianca TCM, da Mata LRF. Impacto da incontinência urinária na qualidade de vida de indivíduos submetidos à prostatectomia radical. Rev. Latino-Am. Enfermagem. 2019;27:e3131. Doi: $10.1590 / 1518-8345.2757 .3131$ 